\title{
Reliability of Thermal strain and stresses in simple bars
}

\author{
${ }^{1}$ T.S.Uma Maheswari, ${ }^{2}$ P.Hari prasad, \\ ${ }^{1}$ Department of Mathematics, Kakatiya University - 506009. A.P. India) \\ ${ }^{21}$ Department of Mathematics, Kakatiya University - 506009. A.P. India)
}

\begin{abstract}
In this paper Reliability of Thermal stresses in simples bars whose body may be expand or contract due to some increase or decrease in the temperature of the body were computed. The thermal stresses or strains may also be found out first by finding out amount of deformation due to change in temperature, and then by finding out thermal strain due to the deformation. The thermal stress may be found out the thermal strain.For such thermal stresses in simple bars we are particularly interested in investigating the reliability by using the linear hazard Rate. It is also compared the results between the reliability of thermal stresses in bars if the ends of the bars are fixed to rigid supports and if the supports yield by an amount equal to $\Delta$.it is observed that the reliability is depending on the coefficient of linear expansion $\propto$. This coefficient of linear expansion is different for each material.
\end{abstract}

Key words: Thermal stresses, temperature, reliability, coefficient of linear expansion, hazard rate

\section{Introduction}

Whenever there is some increase or decrease in the temperature of a body, it causes the body to expand or contract. A little consideration will show that if the body is allowed to expand or contract freely, with the rise or fall of the temperature, no stresses are induced in the body. But if the deformation of the body is prevented, some stresses are induced in the body. Such stresses are called thermal stresses or temperature stresses. The corresponding strains are called the thermal strains or temperature strains.

Reliability is used for developing the equipment manufacturing and delivery to the user. A reliable system is one which operates according to our expectations. Reliability of a system is the probability that a system perform its intended purpose for a given period of time under stated environment conditions. In some cases system failures occur due to certain type of stresses acting on them. These types of system are called stress dependent models of reliability. These models nowadays studied in many branches of science such as Engineering, Medicine, and Pharmaceutical Industries etc [1].

In assessing system reliability it is first necessary to define and categorize different modes of system failures. It is difficult to define failure in unambiguous forms. However a system's performance can deteriorate gradually over time and sometimes there is only a fine line between systems success and system failure. Once the system function and failure modes are explicitly stated reliability can be precisely quantified by probability statements.

\section{Methodology:}

The probability of failure as a function of time can be defined by

$$
F(t)=P(T \leq t), \quad t \geq 0
$$

Where $T$ is a random variable denoting the failure time. Reliability function is defined as the probability of success for the intended time $t$

$$
R(t)=1-F(t)=P(T>t)
$$

The Hazard function $h(t)$ is defined as the limit of the failure rate as the interval approaches zero. Thus the hazard function is the instantaneous failure rates is defined as

$$
z(t)=\frac{f(t)}{R(t)}=\frac{f(t)}{1-F(t)} \quad \text { where } f(t)=\frac{d F(t)}{d t}
$$

Stress dependent hazard models: Basically, the reliability of an item is defined under stated operating and environmental conditions. This implies that any change in these conditions can effect. The failure rate of almost all components is stress dependent. A component can be influenced by more than one kind of stress. For such cases, a power function model of the form [2]

$$
h(t)=z(t) \sigma_{1}{ }^{a} \sigma_{2}{ }^{b}
$$

where $a, b$ are positive constants, $\sigma_{1}$ and $\sigma_{2}$ are stress ratios for two different kinds of stresses, and $z(t)$ is the failure rate at rated stress conditions.

Thermal Stresses In Simple Bars:

The thermal stresses or strains bar may be found out as discussed below: 
The thermal stresses or strains may be found out first by finding out amount of deformation due change in temperature, and then by finding out thermal strain due to the deformation. The thermal stress may now be found out from the thermal strain as usual. Now consider a body subjected to an increase in temperature [3].

Let $\quad l=$ original length of the body,

$\theta=$ increase of temperature and

$\alpha=$ coefficient of linear expansion

$\mathrm{E}=$ modulus of elasticity (young's modulus)

We know that the increase in length due to increase of temperature $\delta l=l . \alpha . \theta$,

If the ends of the bar are fixed to rigid supports, so that its expansion is prevented, then compressive strain induced in the bar.

Stress

$$
\begin{aligned}
& \varepsilon=\frac{\delta l}{l}=l . \alpha \cdot \frac{\theta}{l}=\alpha . \theta \\
& \boldsymbol{\sigma}=\boldsymbol{\varepsilon} . \boldsymbol{E}=\boldsymbol{\alpha} . \boldsymbol{E} \cdot \boldsymbol{\theta}
\end{aligned}
$$

If the supports yield by an amount equal to $\Delta$,then the actual expansion that has taken place,

And strain,

$$
\delta l=l . \alpha . \theta-\Delta
$$

Stress,

$$
\begin{aligned}
\varepsilon=\frac{\delta l}{l} & =\frac{l \cdot \alpha \cdot \theta-\Delta}{l}=\left(\alpha \theta-\frac{\Delta}{l}\right) \\
\boldsymbol{\sigma} & =\boldsymbol{\varepsilon} \cdot \boldsymbol{E}=\left(\boldsymbol{\alpha} \boldsymbol{\theta}-\frac{\Delta}{l}\right) \boldsymbol{E}
\end{aligned}
$$

The Value Of A Coefficient Of Linear Expansion Of Materials In Day Use Is Given Below In Table [4]:

\begin{tabular}{|l|l|c|}
\hline S.NO & MATERIAL & COEFICIENT OF LINEAR EXPANSION $/{ }^{0} \mathrm{C}(\alpha)$ \\
\hline 1 & STEEL & $11.5 \times 10^{-6}$ to $13 \times 10^{-6}$ \\
\hline 2 & $\begin{array}{l}\text { WROGHT IRON,CAST } \\
\text { IRON }\end{array}$ & $11 \times 10^{-6}$ to $12 \times 10^{-6}$ \\
\hline 3 & ALUMINIUM & $23 \times 10^{-6}$ to $24 \times 10^{-6}$ \\
\hline 4 & COPPER,BRASS,BRONZE & $17 \times 10^{-6}$ to $18 \times 10^{-6}$ \\
\hline
\end{tabular}

\section{LINEARLY INCREASING HAZARD MODEL:}

When there is wear or deterioration of parts or components, the failure rate increases with time. The simplest model that we can consider in this category is one in which the Failure Rate increases linearly with time.

$$
\text { Let } \mathrm{z}(\mathrm{t})=\mathrm{kt} \text {, }
$$

where $\mathrm{k}$ is a constant .

$$
\mathrm{h}(\mathrm{t})=\mathrm{z}(\mathrm{t}) \times \sigma
$$

WHEN $\sigma=$ STRESS IN THE BAR IF THE ENDS OF THE BAR ARE FIXED TO RIGID SUPPORTS:

Stress in the bar $\sigma=\alpha . \theta . E$

Therefore Reliability of the bar $\mathrm{R}(\mathrm{t})=\exp \left[-\int_{0}^{t} h(t) d t\right]=\exp \left[-\int_{0}^{t}(z(t) \times \sigma) d t\right]$

$$
=\exp \left[-\int_{0}^{t} k t \times \alpha \cdot \theta \cdot E d t\right]=\exp \left[-k \frac{t^{2}}{2} \times \alpha \cdot \theta \cdot E\right]
$$

WHEN $\sigma=$ STRESS IN THE BAR IF THE SUPPORTS YIELD BY AN AMOUNT EQUAL TO $\Delta$ :

Stress in the bar $\quad \sigma=\left(\alpha \theta-\frac{\Delta}{l}\right) E$

Therefore Reliability of the bar $\mathrm{R}(\mathrm{t})=\exp \left[-\int_{0}^{t} h(t) d t\right]=\exp \left[-\int_{0}^{t}(z(t) \times \sigma) d t\right]$

$$
=\exp \left[-\int_{0}^{t} k t \times\left(\alpha \cdot \theta-\frac{\Delta}{l}\right) E d t\right]=\exp \left[-k \frac{t^{2}}{2} \times\left(\alpha \cdot \theta-\frac{\Delta}{l}\right) E\right]
$$

Example 1: An aluminium alloy bar, fixed at its both ends is heated through 20k.Find the bar material as 80GPa and $24 \times 10^{-6} / \mathrm{K}$.Also find the reliability of the bar for linear hazard models.

Solution: Given $\theta=20 \mathrm{~K}, \mathrm{E}=80 \times 10^{3} \mathrm{~N} / \mathrm{mm}^{2}$, Coefficient of linear expansion $\alpha=24 \times 10^{-6} / \mathrm{K}$

$$
\sigma=\alpha . \theta . E=24 \times 10^{-6} .20 .80 \times 10^{3}=38.4 \mathrm{~N} / \mathrm{mm}^{2}=38.4 \mathrm{MPa}
$$

The Reliability of bar is $\mathrm{R}(\mathrm{t})=\exp \left[-k \frac{t^{2}}{2} \times \alpha \cdot \theta \cdot E\right]=0.9810$ when $\mathrm{k}=0.1$ and $\mathrm{t}=0.1$

Example 2: Two parallel walls $6 \mathrm{~m}$ apart are stayed together by a steel rod $25 \mathrm{~mm}$ diameter passing through metal plates and nuts at each end. The nuts are tightened home, when the rod is at a temperature of $100^{\circ} \mathrm{C}$.Determine the stress in the rod, when the temperature falls down to $60^{\circ} \mathrm{C}$, if the ends yield by $1 \mathrm{~mm}$. Take $\mathrm{E}=200 \mathrm{GPa}$ and $\alpha=12 \times 10^{-6} /{ }^{\circ} \mathrm{C}$

Solution: Given $1=6 \mathrm{~m}=6 \times 10^{3} \mathrm{~mm}$, Diameter $(\mathrm{d})=25 \mathrm{~mm}$;Decrease in temperature $(\theta)=100-60=40^{\circ} \mathrm{C}$; amount of yield in ends $(\Delta)=1 \mathrm{~mm}$; Modulus of elasticity $(\mathrm{E})=200 \mathrm{GPa}=200 \times 10^{3} \mathrm{~N} / \mathrm{mm}^{2}$; Coefficient of linear expansion $\alpha=12 \times 10^{-6^{\circ}} \mathrm{C}$

Stress $\sigma=\left(\boldsymbol{\alpha} \boldsymbol{\theta}-\frac{\Delta}{\boldsymbol{l}}\right) \boldsymbol{E}=12 \times 10^{-6^{\circ}} .40^{\circ}-\frac{1}{6 \times 10^{3}}=96 \mathrm{~N} / \mathrm{mm}^{2}=96 \mathrm{MPa}$ 
The Reliability of the bar $\mathrm{R}(\mathrm{t})=\exp \left[-k \frac{t^{2}}{2} \times\left(\alpha . \theta-\frac{\Delta}{l}\right) E\right]=0.9531$

\section{Reliability Computations}

Reliability computations for simple bars when $\sigma=$ Stress in the rod if the ends do not yield:

Table-1[Aluminium alloy]

\begin{tabular}{|c|l|l|l|l|}
\hline \multicolumn{5}{|l|}{ when $\mathrm{t}=0.1, \quad \alpha=24 * 10^{-6}}$, \\
\hline & & \multicolumn{2}{l|}{} \\
$k$ & $\theta$ & $\mathrm{E}$ & $\sigma$ & $\mathrm{R}(\mathrm{t})$ \\
\hline 0.01 & 20 & 80000 & 38.4 & 0.9623279 \\
\hline 0.02 & 20 & 80000 & 38.4 & 0.9260750 \\
\hline 0.03 & 20 & 80000 & 38.4 & 0.8911878 \\
\hline 0.04 & 20 & 80000 & 38.4 & 0.857615 \\
\hline 0.05 & 20 & 80000 & 38.4 & 0.8253068 \\
\hline 0.06 & 20 & 80000 & 38.4 & 0.7942158 \\
\hline 0.07 & 20 & 80000 & 38.4 & 0.7642961 \\
\hline 0.08 & 20 & 80000 & 38.4 & 0.7355034 \\
\hline 0.09 & 20 & 80000 & 38.4 & 0.7077955 \\
\hline 0.1 & 20 & 80000 & 38.4 & 0.6811314 \\
\hline
\end{tabular}

Table-2[Aluminium alloy]

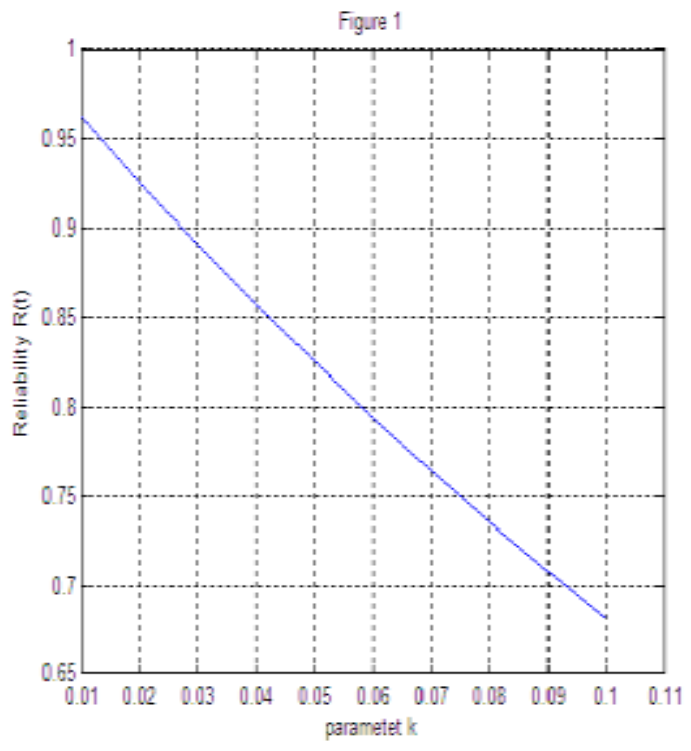

Table-3[Aluminium alloy]

\begin{tabular}{|c|c|l|c|l|}
\hline \multicolumn{5}{|c|}{ when $\mathrm{k}=0.1, \mathrm{t}=1$} \\
\hline$\alpha$ & $\theta$ & $\mathrm{E}$ & $\sigma$ & $\mathrm{R}(\mathrm{t})$ \\
\hline $24 \times 10^{-6}$ & 20 & 10000 & 4.8 & 0.786628 \\
\hline $24 \times 10^{-6}$ & 20 & 50000 & 24 & 0.301194 \\
\hline $24 \times 10^{-6}$ & 20 & 100000 & 48 & 0.090718 \\
\hline $24 \times 10^{-6}$ & 20 & 200000 & 96 & 0.00823 \\
\hline $24 \times 10^{-6}$ & 20 & 50000 & 24 & 0.301194 \\
\hline $24 \times 10^{-6}$ & 20 & 60000 & 28.8 & 0.236928 \\
\hline $24 \times 10^{-6}$ & 20 & 70000 & 33.6 & 0.186374 \\
\hline $24 \times 10^{-6}$ & 20 & 80000 & 38.4 & 0.146607 \\
\hline $24 \times 10^{-6}$ & 20 & 90000 & 43.2 & 0.115325 \\
\hline $24 \times 10^{-6}$ & 20 & 10000 & 4.8 & 0.786628 \\
\hline
\end{tabular}

\begin{tabular}{|l|l|l|l|l|}
\hline \multicolumn{2}{|c|}{ when } & $\mathrm{k}=0.01, \quad \alpha=24 \times 10^{-6}$ \\
\hline $\mathrm{t}$ & $\theta$ & $\mathrm{E}$ & $\sigma$ & $\mathrm{R}(\mathrm{t})$ \\
\hline 0.1 & 20 & 80000 & 38.4 & 0.998081 \\
\hline 0.2 & 20 & 80000 & 38.4 & 0.926075 \\
\hline 0.3 & 20 & 80000 & 38.4 & 0.891187 \\
\hline 0.4 & 20 & 80000 & 38.4 & 0.85761 \\
\hline 0.5 & 20 & 80000 & 38.4 & 0.825306 \\
\hline 0.6 & 20 & 80000 & 38.4 & 0.794215 \\
\hline 0.7 & 20 & 80000 & 38.4 & 0.76429 \\
\hline 0.8 & 20 & 80000 & 38.4 & 0.735503 \\
\hline 0.9 & 20 & 80000 & 38.4 & 0.707795 \\
\hline 1 & 20 & 80000 & 38.4 & 0.681131 \\
\hline
\end{tabular}

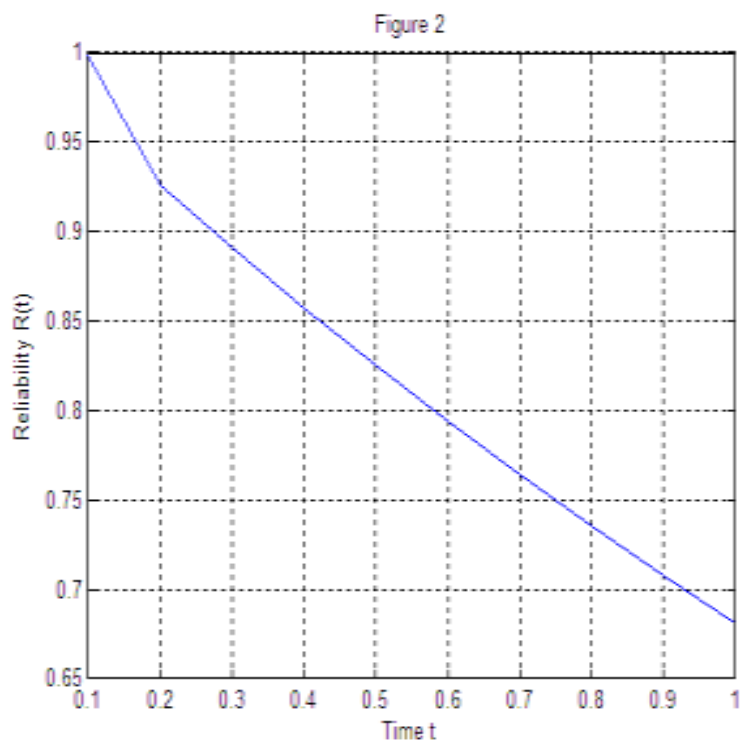

Table-4[Steel]

\begin{tabular}{|c|c|l|l|l|}
\hline when $\mathrm{k}=0.01, \quad \mathrm{t}=.01$ & & \\
\hline$\alpha$ & $\theta$ & $\mathrm{E}$ & \multicolumn{1}{|l|}{$\sigma$} & $\mathrm{R}(\mathrm{t})$ \\
\hline $11.5 \times 10^{-6}$ & 20 & 10000 & 2.3 & 0.999885 \\
\hline $11.5 \times 10^{-6}$ & 20 & 20000 & 4.6 & 0.9908421 \\
\hline $11.5 \times 10^{-6}$ & 20 & 30000 & 6.9 & 0.979512 \\
\hline $11.5 \times 10^{-6}$ & 20 & 40000 & 9.2 & 0.9638688 \\
\hline $11.5 \times 10^{-6}$ & 20 & 50000 & 11.5 & 0.9441218 \\
\hline $11.5 \times 10^{-6}$ & 20 & 60000 & 13.8 & 0.9205352 \\
\hline $11.5 \times 10^{-6}$ & 20 & 70000 & 16.1 & 0.893418 \\
\hline $11.5 \times 10^{-6}$ & 20 & 80000 & 18.4 & 0.863121 \\
\hline $11.5 \times 10^{-6}$ & 20 & 90000 & 20.7 & 0.8300245 \\
\hline $11.5 \times 10^{-6}$ & 20 & 100000 & 23 & 0.7945336 \\
\hline
\end{tabular}



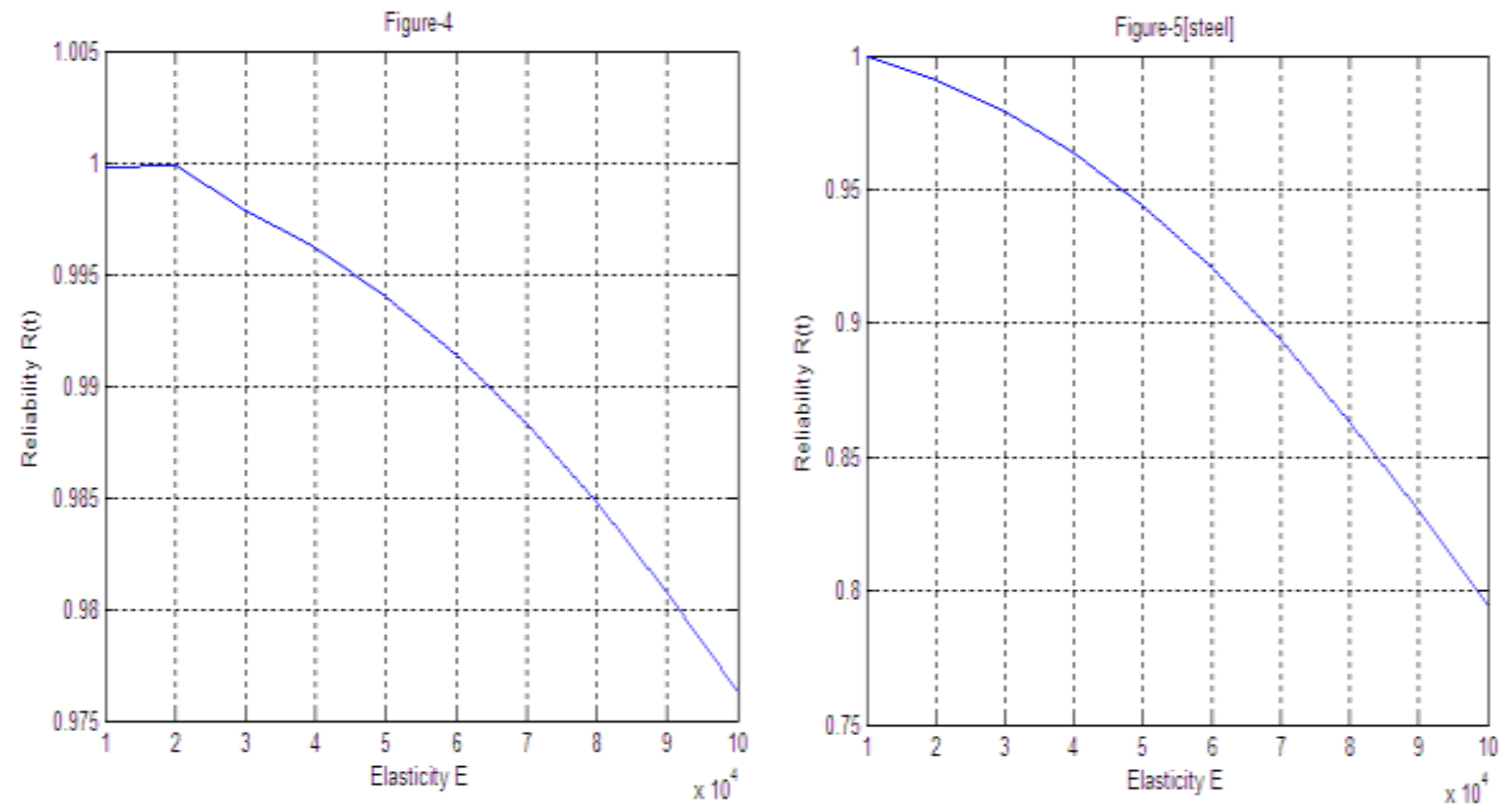

Reliability computations for simple bars when $\sigma=$ Stress in the rod if the ends yield by an amount equal to $\Delta$ :

\begin{tabular}{|l|l|l|l|l|}
\hline \multicolumn{5}{|l}{ when } \\
\hline & $\mathrm{k}=0.01, \alpha=12 \times 10^{-6}, \mathrm{l}=6000, \Delta=1$ \\
\hline $\mathrm{t}$ & $\theta$ & $\mathrm{E}$ & $\sigma$ & $\mathrm{R}(\mathrm{t})$ \\
\hline 0.01 & 40 & 200000 & 62.7 & 0.999969 \\
\hline 0.02 & 40 & 200000 & 62.7 & 0.999875 \\
\hline 0.03 & 40 & 200000 & 62.7 & 0.999718 \\
\hline 0.04 & 40 & 200000 & 62.7 & 0.999499 \\
\hline 0.05 & 40 & 200000 & 62.7 & 0.999217 \\
\hline 0.06 & 40 & 200000 & 62.7 & 0.998873 \\
\hline 0.07 & 40 & 200000 & 62.7 & 0.998466 \\
\hline 0.08 & 40 & 200000 & 62.7 & 0.997997 \\
\hline 0.09 & 40 & 200000 & 62.7 & 0.997465 \\
\hline 0.1 & 40 & 200000 & 62.7 & 0.996872 \\
\hline
\end{tabular}

\begin{tabular}{|c|c|l|l|l|}
\hline when $\mathrm{k}=0.01, \quad \mathrm{t}=.01, \Delta=1, \mathrm{l}=6000$ \\
\hline$\alpha$ & $\theta$ & $\mathrm{E}$ & $\sigma$ & $\mathrm{R}(\mathrm{t})$ \\
\hline $12 \times 10^{-6}$ & 100 & 200000 & 207 & 0.98972 \\
\hline $12 \times 10^{-6}$ & 200 & 200000 & 447 & 0.977914 \\
\hline $12 \times 10^{-6}$ & 300 & 200000 & 687 & 0.966249 \\
\hline $12 \times 10^{-6}$ & 400 & 200000 & 927 & 0.954724 \\
\hline $12 \times 10^{-6}$ & 500 & 200000 & 1170 & 0.943335 \\
\hline $12 \times 10^{-6}$ & 600 & 200000 & 1410 & 0.932083 \\
\hline $12 \times 10^{-6}$ & 700 & 200000 & 1650 & 0.920965 \\
\hline $12 \times 10^{-6}$ & 800 & 200000 & 1890 & 0.909979 \\
\hline $12 \times 10^{-6}$ & 900 & 200000 & 2130 & 0.899125 \\
\hline $12 \times 10^{-6}$ & 1000 & 200000 & 2370 & 0.8884 \\
\hline
\end{tabular}
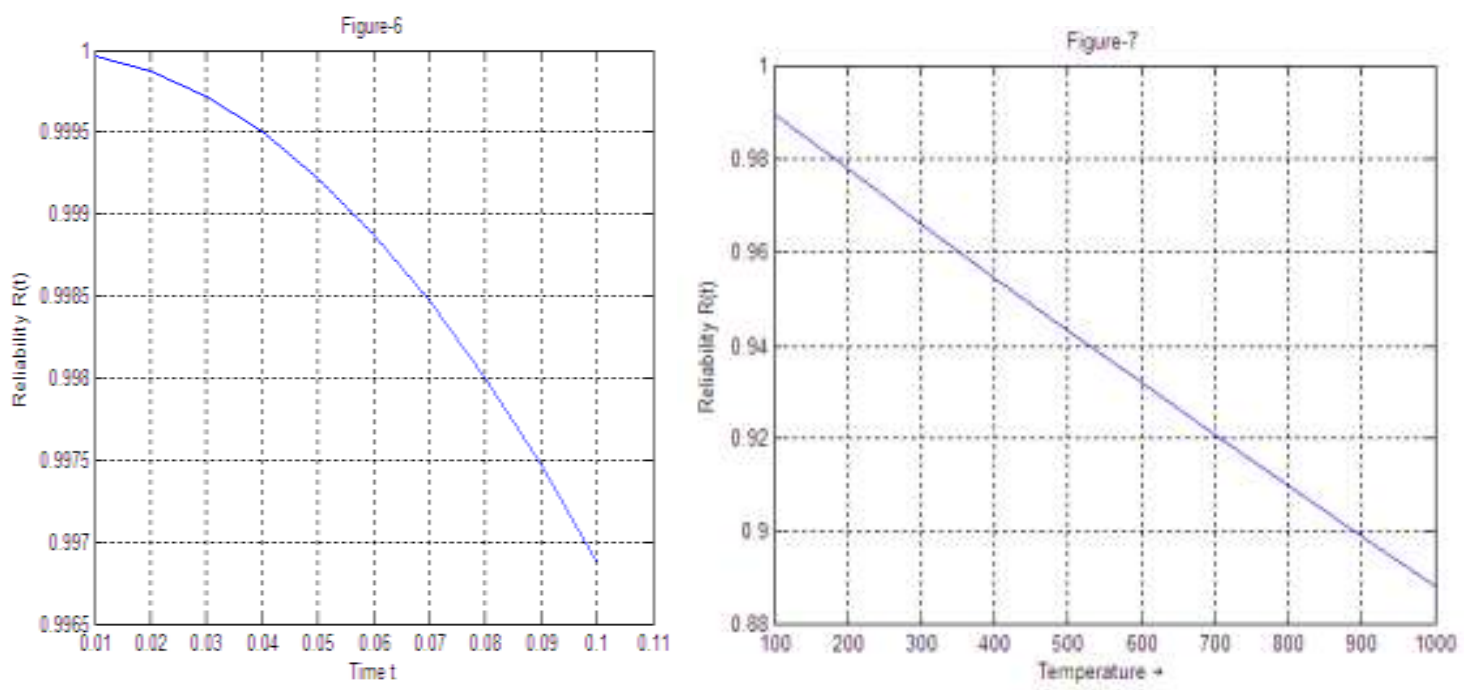
Table-7[Iron]

\begin{tabular}{|c|c|c|c|c|}
\hline when & \multicolumn{4}{|c|}{$\mathrm{k}=0.1, t=0.1 \alpha=12 \times 10^{-6}, \mathrm{l}=6000$} \\
\hline$\Delta$ & $\theta$ & $\mathrm{E}$ & $\sigma$ & $\mathrm{R}(\mathrm{t})$ \\
\hline 1 & 100 & 200000 & 207 & 0.901826 \\
\hline 0.9 & 100 & 200000 & 210 & 0.900325 \\
\hline 0.8 & 100 & 200000 & 213 & 0.898825 \\
\hline 0.7 & 100 & 200000 & 217 & 0.897328 \\
\hline 0.6 & 100 & 200000 & 220 & 0.895834 \\
\hline 0.5 & 100 & 200000 & 223 & 0.894342 \\
\hline 0.4 & 100 & 200000 & 227 & 0.892853 \\
\hline 0.3 & 100 & 200000 & 230 & 0.891366 \\
\hline 0.2 & 100 & 200000 & 233 & 0.889882 \\
\hline 0.1 & 100 & 200000 & 237 & 0.8884 \\
\hline
\end{tabular}

Table-8[Copper]

\begin{tabular}{|l|c|l|l|l|}
\hline when & $\mathrm{k}=0.01, \mathrm{t}=1, \Delta=1,1 \alpha=17 \times 10^{-6}$ \\
\hline & $\theta$ & $\mathrm{E}$ & $\sigma$ & $\mathrm{R}(\mathrm{t})$ \\
\hline 10000 & 40 & 200000 & 116 & 0.559898 \\
\hline 20000 & 40 & 200000 & 126 & 0.532592 \\
\hline 30000 & 40 & 200000 & 129 & 0.523789 \\
\hline 40000 & 40 & 200000 & 131 & 0.519442 \\
\hline 50000 & 40 & 200000 & 132 & 0.516851 \\
\hline 60000 & 40 & 200000 & 133 & 0.515131 \\
\hline 70000 & 40 & 200000 & 133 & 0.513906 \\
\hline 80000 & 40 & 200000 & 134 & 0.512989 \\
\hline 90000 & 40 & 200000 & 134 & 0.512277 \\
\hline 100000 & 40 & 200000 & 134 & 0.511709 \\
\hline
\end{tabular}
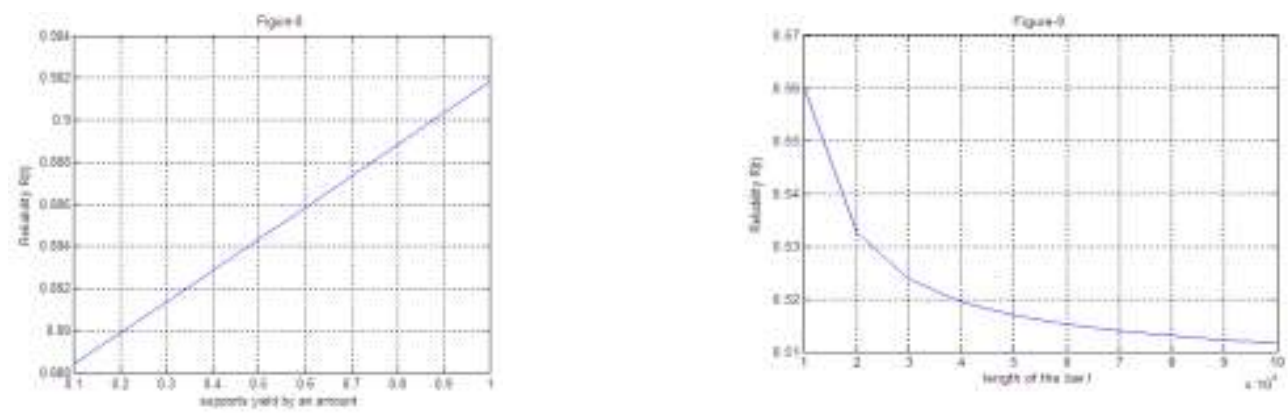

II. Conclusions:

Reliability of the Thermal stresses or strains are found out first by finding out amount of deformation due to change in temperature, and then by finding out thermal strain due to the deformation. Reliability computations are obtained for simple bars when stress $(\sigma)$ in the Rod i) if the ends do not yield and ii) if the ends yield by an equal to amount $\Delta$ for various Materials. when temperature increases Reliability decreases. It is also compared the results between the reliability of thermal stresses in bars if the ends of the bars are fixed to rigid supports and if the supports yield by an amount equal to $\Delta$.It is observed that the reliability is depending on the coefficient of linear expansion $\propto$.This coefficient of linear expansion is different for each material.

\section{References}

[1] Kapur, K.C and L.R.Lamberson (1977): Reliability in Engineering Design, Jhon Wiley and Sons, In., NewYork

[2] T.S.Uma Maheswari (1991): Studies on some Stress-Strength reliability models, Ph.D.Thesis, Kakatiya University, Warangal.

[3] Abu-Bakr Iris (2007): Reliability Analysis of Simply Supported Steel Beams

[4] Australian Journal of Basic and Applied Sciences, 1(1): 20-29, 2007, INSInet Publication

[5] R.S. KHURMI, Strength of Materials [Mechanical of Solids], S. Chand Publications

[6] Lorenzo Bardella (2008): Reliability of First Order Shear Deformation Models for Sandwich Beams, Journal of Mechanics of Materials and Structures, Vol. 3, No.7, 2008 